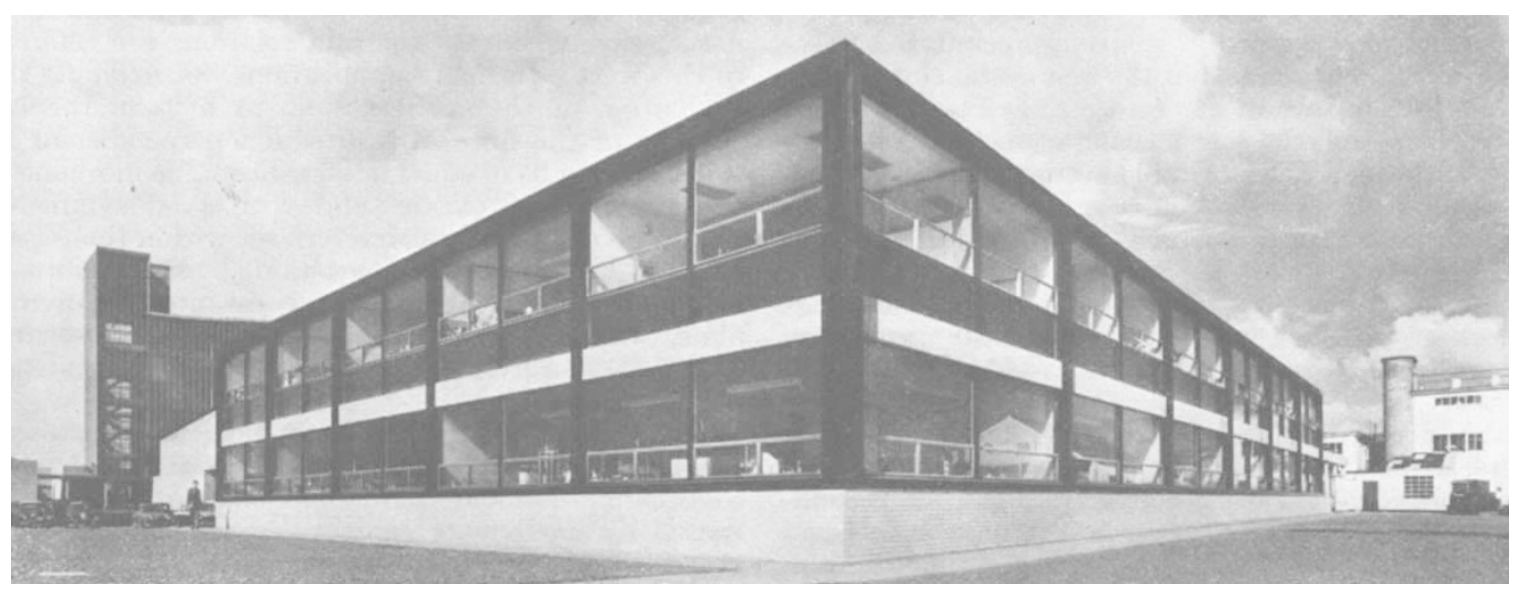

Fig. 1. The new Ciba (A.R.L.) research laboratories

possible uses of plastics in many fields. The new group is divided into seven teams, each of which is investigating some distinct aspect of the problem, including the synthesis of new raw materials and the pursuit of now condensation and polymerization processes. In addition to the usual equipment required for this type of work, the department has an analytical section where particular emphasis is given to infra-red and ultra-violet spectrophotometric and vapour-phase chromatographic analysis. The ground floor also contains a central chemical and glassware store and a glass-blowing room, and there is easy access to the library, which has also been expanded to meet the increased requirements.

The addition to the research staff at Duxford brings the proportion of those employed in laboratories on research, application, formulation and quality control to twenty per cent of the total staff employed. It is clear that the laboratory work can be greatly assisted by the use of modern and automatic equipment and wherever possible this is done, but the quality and quantity of these investigations are still dependent upon the individual skill, knowledge and efforts of the scientist and technician, and every new field entered necessitates an increase in the laboratory staff. In contrast to this, the factory has repeatedly been able to increase the volume of production without proportional increases in the labour force employed, and this has been possible only by the continuous introduction of fully automatic processes. An outstanding example of this is provided by the new plant, which is now in production, for the manufacture of epoxy resins--resins based upon the condensation of diphenylol propane with epichlorhydrin. This plant--although it has a working area of more than 16,000 square feet, several types of reaction vessel and ancillary distillation units with miles of pipe work and more than 500 valves-is maintained by only three men per shift and has more than five times the capacity of the plant it replaces. In the new plant the equipment has been designed with the view of minimizing fire hazards; the building itself is of concrete and glass with dished floors to contain spillages, is well ventilated and sited away from the tank farm for the inflammable solvents used in the process, and also from the accompanying control laboratory and switch-house.

These new facilities, continuing the programme of expansion of both research and production, demonstrate the rapid growth of the industry and the faith of those who have determined this growth from the modest beginnings of the early 1930 's. R. F. WEBB

\title{
THE ATOMIC ENERGY AUTHORITY
}

\section{REPORT FOR 1\$58-59}

$\mathrm{T}$ HE fifth annual report (pp. vii $+68+4$ plates. London: H.M. Stationery Office, 1959. 5s. net) of the Atomic Energy Authority and the last to be issued over Sir Edwin Plowden's signature, who is being succeeded as chairman by Sir Roger Makins on January 1, 1960, covers the year ended March 31, 1959. In that year work started on construction at Windscale of the advanced gas-cooled reactor prototype, the last of the four Calder Hall reactors became critical on December 8, 1958, the first reactor at Chapelcross came into use for generating electricity on February 25, 1959, and the Authority's staff increased from 30,341 to 35,260 . No final decision has been reached regarding the transfer from Harwell to Winfrith Heath of the whole of controlled thermonuclear project. The terms of the first contract for the supply of fuel for a nuclear power station overseas -the Latina station of Agip Nucleare-were negotiated during the year. The Industrial Group has been divided into two groups: development and engineering, under Sir William Cook, and production, under Sir Leonard Owen; executive, as well as functional, responsibility has now been restored to the technical members of the Board.

The report reviews briefly progress made during the past five years in the application of nuclear energy, during which the first five large-scale nuclear power stations came into operation: besides Calder Hall and Chapelcross, the United States $60 \mathrm{MW}$. pressurized water reactor power station at Shippingport, the French 30 MW. gas-cooled, graphite-moderated reactor power station at Marcoule and the U.S.S.R. 
100 MW. graphite-moderated, water-cooled reactor power station in Siberia. In the United Kingdom gas-cooled, graphite-moderated reactors developing towards exit gas temperatures of $550^{\circ} \mathrm{C}$. and $750^{\circ} \mathrm{C}$. promise to lead to higher efficiency and ratings and a 30 per cent fall in capital costs of nuclear power stations is predicted with the development of the present main types. The application of radioactive isotopes continues to grow, including the use in industry of control instruments based on radioactive isotopes, such as thickness gauges. Total sales of radioisotopes and related products rose from $£ 650,000$ to $£ 800,000$, the proportion exported remaining at about 60 per cent, to 55 countries. Plans for the extraction of radiocasium from radioactive waste are being considered in the United Kingdom and the potential output amounts to tens of millions of curies per annum. In raw materials, developments during the year confirmed that the present over-supply of uranium is likely to persist at least until the late 1960 's, and the uranium requirements of the free world's current military and civil programmes can now be met by mines already in production, and it seems likely that the forward price of uranium may fall below 8 dollars per pound.

Apart from its first aim of ensuring the successful construction and operation of the nuclear power stations now under construction for the electricity boards, the Authority's reactor development programme comprises extensive work on the development of more advanced types of reactor, the aim of which is to provide progressively cheaper sources of nuclear power, and here the achievement of lower capital costs is a major objective. Efforts are being made to develop ways of using as fuel the plutonium that will gradually become available from the burning of uranium in the early stations. Beyond the natural uranium reactors two stages of development are envisaged. First, the advanced gas-cooled reactor and the water-modulated reactors seek to attain lower capital costs by using slightly enriched fuel. Secondly, the high-temperature gas-cooled reactor being developed at Winfrith Heath as a joint project with other member countries of the European Nuclear Energy Agency, and the fast breeder reactor at Dounreay are characterized by both low capital costs and negligible net fissile fuel consumption. While the present type of gas-cooled, graphitemoderated reactor may command a market overseas where large stations are required, the report points out that considerable advances in nuclear technology will be required before smaller reactors $(20-100 \mathrm{MW}$.) become competitive in normal circumstances. The study of plutonium utilization in reactors continued as well as reactor physics studies in several zero energy reactors.

The report summarizes further research on controlled thermonuclear reactions. The main object of the present experimental programme on Zeta and Sceptre III is to discover the reason for the excessive loss of energy to the torus walls during the current failure. Work on smaller-scale gas-discharge devices was considerably expanded and some of the formidable technological problems involved in building a thermonuclear reactor are being studied. An Advisory Committee under the chairmanship of the Board Member for Scientific Research was set up in December 1958 to examine and keep under review all aspects of the Authority's research programme on controlled thermonuclear reactions, to advise the Member responsible for research policy on the merits of proposals for new work, and to make recommendations on changes in policy which seem necessary. Other research and development work being carried out by the Research Group, the Industrial Group and the Weapons Group is also briefly summarized. The first ranges from metallurgy, the physics of the solid state to work on particle accelerators. That of the Industrial Group extends far beyond the Group's laboratories, and extramural agreements between the Group and universities, research associations and industry now accounts for about a tenth of the Group's annual expenditure on research and development. That of the Weapons Group is illustrated by its examination of soluble chelate complexes of the alkaline earth metal ions and by its measurements of particle size, including use of a centrifugal system to increase the rate of sedimentation with the photo-sedimentometer.

Since its establishment in 1958 under the chairmanship of Sir Douglas Veale, the committee advising the Authority on the supply of specialized health and safety staff has had detailed consultations with many Government departments, hospitals, universities and industry. An interim report to the Authority recommended the initiation of courses in radiobiology and radiological physics at selected universities and provision of studentships if possible for the 1959-60 academic year. This recommendation has been accepted in principle by the Authority and details of the scheme are being worked out in collaboration with the University Grants Committee and the Department of Scientific and Industrial Research. The amount of research and development work contracted out by the Authority continues to increase and more than three hundred professional staff and technical staff from industry have worked with Authority staff during the year.

\section{THE INSTITUTE OF PHYSICS}

T HE main sections of the thirty-ninth annual report of the Board of the Institute of Physics for 1958 (Pp. 18. London: Institute of Physics, 1959), which was presented to the annual general meeting of the Institute on July 7, deal with membership, examinations, education and publications. During the year, 851 applications for election or transfer to the various grades of membership were received. The total membership increased by 415 to 6,309 , with a slight decrease in the number of subscribers (430 compared with 453 in 1957), but with fairly large increases in the associateship and student membership grades. Seven technical colleges which had applied for recognition as institutions possessing courses of study approved for the purpose of the membership regulations were visited by representatives of the membership and examinations committee and six of the applications were approved. In addition, the application by the Borough Polytechnic, London, for recognition of courses on which the Diploma of Technology in physics is awarded was granted. Twenty-six of the eightv candidates 